\title{
Effective Stress and Compressibility of Unsaturated Clayey Soil under Drying and Wetting Cycles
}

\author{
Mehrdad Kholghifard ${ }^{1 *}$ \\ ${ }^{1}$ Department of Civil Engineering, Yasooj Branch, Islamic Azad University, 7591493686 Yasooj, Iran \\ * Corresponding author, e-mail: kholghifard.m@iauyasooj.ac.ir
}

Received: 11 April 2020, Accepted: 07 June 2020, Published online: 27 July 2020

\begin{abstract}
Naturally, soil moisture reduces during dry seasons when the soil is in drying state; while it increases during wet seasons when the soil is in wetting state. Previous studies have shown that for an unsaturated soil sample, soil-water characteristic curves (SWCCs) do not match in wetting and drying paths. The differences between wetting and drying paths are called the hydraulic hysteresis. The hydraulic hysteresis plays an important role in mechanical properties of soil such as shear strength, volume change, and settlement. The objective of this research is to study the effects of drying and wetting on the effective stress and compressibility of unsaturated clayey fine-grained soils. To this end, saturated and unsaturated triaxial tests were performed on the soil samples under various normal mean stresses, and matrix suctions in drying and wetting paths. It was found that soil samples bear higher levels of effective stress in the drying path than the wetting path under a same level of suction. The attained values of effective stress parameter $(\chi)$ showed that the Bishop's effective stress parameter $(\chi=S r)$ is not properly applicable for the clayey soil. Moreover, the resulting loading-collapse curve (LC) revealed that the effective pre-consolidation pressure in the drying and wetting stages changed even with same degrees of matrix suction.
\end{abstract}

\section{Keywords}

unsaturated soil, drying and wetting, effective stress, compressibility

\section{Introduction}

The environmental conditions of every region are determined by its weather. One of the most important factors in environmental condition is the moisture (water content) of the soil. Any variation of the moisture condition in a region affects its soil conditions. So, in its natural condition, soil is neither fully saturated nor fully dry. In such conditions, soil is normally referred to as semi-saturated or the so called unsaturated. Those layers of soil exposed to the Earth's surface are more influenced by atmospheric, environmental, and physical factors, therefore their water content changes more frequently. This mostly applies to dry and semi-dry regions such as Iran. Such conditions can cause severe irreversible damages to foundations, buildings and structures build on such soils.

Conventional soil mechanics theory treats soil as either fully saturated or completely dry. A large number of geotechnical problems involve the presence of partially saturated soil zones where voids between soil particles are filled with a mixture of air and water. These zones are often ignored in practice and the soil is assumed to be either fully saturated or completely dry. Changes in soil suction that are related to changes in water content significantly affect the constitutive behavior of unsaturated soils. For that reason, the effects of suction change on the hydro-mechanical behavior of soils such as shear strength and volume change behavior (swelling or collapse) are the main concern when solving geotechnical engineering problems. Strength of a saturated cohesive soil is lower than the strength of the same unsaturated soil depending on the loading conditions [1].

Changes of the water content of unsaturated soils are depicted on a diagram showing the relation between the soil water content and suction in the pore fluid. This diagram is known as the soil-water characteristic curve (SWCC). There is considerable difference between the curves in the drying (increased matrix suction) and wetting (decreased 
matrix suction) phases. The difference is caused by a phenomenon called hydraulic hysteresis, which plays a significant role in controlling soil properties such as shear strength, volume variation, and settlement.

Currently there are two distinct theories for explaining the mechanical behavior of unsaturated soils. The first theory was developed on the effective stress principle by Bishop [2] known as effective stress approach for unsaturated soil. On the other hand, Fredlund et al. [3] suggested that two independent variables namely matric suction and net normal stress are essential to describe the behavior of unsaturated soils.

Bishop was the first who developed theory of the mechanical behavior of unsaturated soil (including its shear strength and volume variation) based on the effective stress. In this theory, effective stress is expressed as a function of externally applied stress and internal water pressure (Eq. (1)):

$p^{\prime}=p-u_{a}+\chi\left(u_{a}-u_{w}\right)$,

where, $p^{\prime}$ denotes effective stress, $p$ shows total stress, and $u_{a}$ indicates pore air pressure. In addition, $u_{w}, u_{a}-u_{w}$, and $\chi$ stand for pore water pressure, matrix suction and effective stress parameter, respectively. According to Bishop's studies, $\chi$ depends on the degree of saturation $(\mathrm{Sr})$, it is equal to 1 for saturated soils and is equal to zero for unsaturated soils. However, later on researchers deeply discussed this parameter and corrected its values. The main limitation of the effective stress principle was that no unique relationship existed between the degree of saturation $(S r)$ and the effective stress parameter $(\chi)$ [3]. To overcome the above mentioned limitation of the effective stress approach, Khalili et al. [4] proposed the following relation for the relationship between effective stress parameter $(\chi)$ and matrix suction ration in the transition from saturated to unsaturated conditions. This relation can be applied to both decreased suction (wetting) and increased suction (drying) states:

$\chi=\left\{\begin{array}{lll}1 & \text { for } s \leq s_{e} \\ {\left[\frac{s}{s_{e}}\right]^{-\gamma}} & \text { for } s \geq s_{e}\end{array}\right.$,

where $s=u_{a}-u_{w}$ is matric suction, $s_{e}$ is suction value at the transition between saturated and unsaturated state and $\gamma$ is considered as a material-independent constant and its value for the best-fit curve is 0.55 . For wetting processes, $s_{e}$ is equal to the air expulsion value $\left(s_{e x}\right)$, whereas for drying processes, $s_{e}$ is equal to the air entry value $\left(s_{e a}\right)$. On the other hand, Fredlund et al. [3] proposed that the constitutive behavior of unsaturated soils should be described using two independent stress variables, namely net normal stress $\left(\sigma-u_{a}\right)$ and matric suction $\left(u_{a}-u_{w}\right)$. Similarly, Fredlund and Rahardjo [5] suggested using net stress and matric suction to describe the mechanical behavior of unsaturated soils as below:

$\tau=c^{\prime}+\left(\sigma-u_{a}\right) \tan \varphi^{\prime}+\left(u_{a}-u_{w}\right) \tan \varphi^{b}$,

where $\tau$ is shear strength, $c^{\prime}$ is effective cohesion, $\varphi^{b}$ is angle of internal friction related to the matric suction (angle that indicates the increase of the effective cohesion due to the matric suction) and $\varphi^{\prime}$ is effective friction angle.

The stress state variables approach has been widely advocated in the literature, but has found very little application in practice [6].The approach requires extensive and time consuming laboratory testing to determine the material parameters, particularly for fine-grained materials, in which the coefficient of permeability of the material is very low. The equipment used for this purpose is usually expensive and complex, and the level of expertise required for the determination of $\varphi^{b}$ is often beyond that of many geotechnical engineering laboratories.

The main advantage of the effective stress method is its simplicity as well as the ease of determining its necessary parameters through normal laboratory tests. Moreover, defining the effective stress parameter $(\chi)$ as a function of suction, rather than degree of saturation, enables development of elasto-plastic models with better predictive capacity [3]. Based on the review, $\chi$ is a significant and effective parameter in mechanical behavior (e.g. effective stress, volume change, and shear strength) of unsaturated soils. As pointed out by researchers, $\chi$ is a parameter strongly related to soil structure which can be different for various soils. However, there is still no unique relationship between $\chi$ and $S r$.

Many hydro-mechanical models for unsaturated soils are developed based on Bishop's theory of effective stress. One of the characteristics of unsaturated soil in these models is the curve for variations of effective pre-consolidation stress or flow limit versus matrix suction, which is known as the loading-collapse curve. In 2002, Loret and Khalili [7] stated that the shape of the LC curve and the rate of reduction in effective stress control the collapse behavior of soil at the time of moisture absorption. Although the LC curve has been obtained for several hydraulic models, the effect of hydraulic hysteresis on this curve is not 
understood completely. Kholghifard et al. [8, 9] found that drying and wetting phenomena significantly affect collapsibility behavior of residual granite soils.

The present research was mainly aimed at analyzing the behavior of effective stress parameter $(\chi)$ and LC curve of the fine-grained soil in Yasuj (Iran) under drying and wetting cycles using a modified triaxial apparatus. In order to validate the results, a comparison was drawn between the results of this study and those of previous studies by Bishop [2] and Khalili et al. [4].

\section{Materials and methods}

\subsection{Preparing soil samples}

Soil samples were gathered from the surroundings of Yasuj at depths of 1.5 to $2.5 \mathrm{~m}$. Fig. 1 shows the grading curve for the soil samples. Table 1 summarizes properties of the soil samples. The basic properties of the samples obtained from the two regions were almost similar. According to the Unified Soil Classification System (USCS) the soil was identified as CL-ML silty clay of low plasticity.

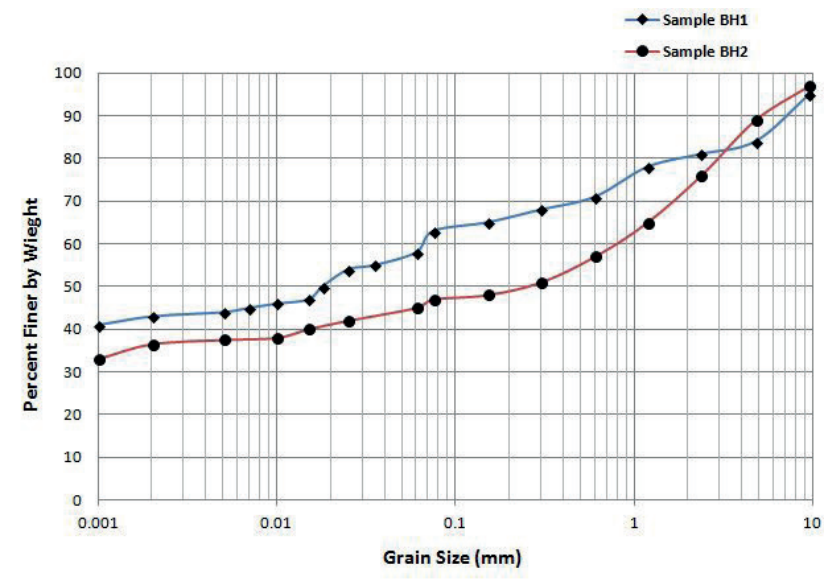

Fig. 1 Particle size distribution of the soil samples

Table 1 Basic properties of the soil samples

\begin{tabular}{lc}
\hline Property & Value \\
\hline Liquid Limit (\%) & 22 \\
Plastic Limit (\%) & 8 \\
Plasticity Index (\%) & 14 \\
Specific gravity & 2.63 \\
Gravel (\%) & 6 \\
Sand (\%) & 34 \\
Silt \& Clay (\%) & 60 \\
Optimum moisture content $(\%)$ & 18.3 \\
Maximum dry density $\left(\mathrm{Mg} / \mathrm{m}^{3}\right)$ & 15.2 \\
Natural dry density $\left(\mathrm{Mg} / \mathrm{m}^{3}\right)$ & 22.6 \\
Natural water content $(\%)$ & 12.9 \\
\hline
\end{tabular}

In order to prepare the soil samples required for the tests, adequate amount of soil was dried by a 10-day exposure to air and then lumps were crushed using a plastic hammer. The resulting soil passed through a 0.425 sieve. Next, an adequate amount of soil was fully mixed with $22.6 \%$ of water (natural moisture of the soil in the region). Prior to compaction, wet soil samples were kept in a close plastic container for 48 hours in order to balance their moisture. According to the method proposed by ASTM D-6836 [10], in order to obtain uniform homogenous samples, a specific amount of soil was pounded in the mould with bulk density of $12.9 \mathrm{kN} / \mathrm{m}^{3}$ (83\% relative compaction) using the static compaction method in conditions similar to natural conditions.

\subsection{Modified unsaturated triaxial apparatus}

Fig. 2 shows the schematic design and a view of different parts of the modified Bishop-Wesley [11] apparatus. This device was designed and built to perform tri-axial tests on unsaturated soil samples with a controlled stress path. It includes three main components: a double-layer cell, a control and loading panel, and an information processing system. The cell incorporated into this device has an internal and an external container designed to independently measure the total volume variation and variation of pore water content of soil samples during the test. The control and loading panel is composed of volume variation displays, derange system, and load and pressure application system. For application of vertical loads, cell pressure, pore water pressure, three pressure control cylinders are used.

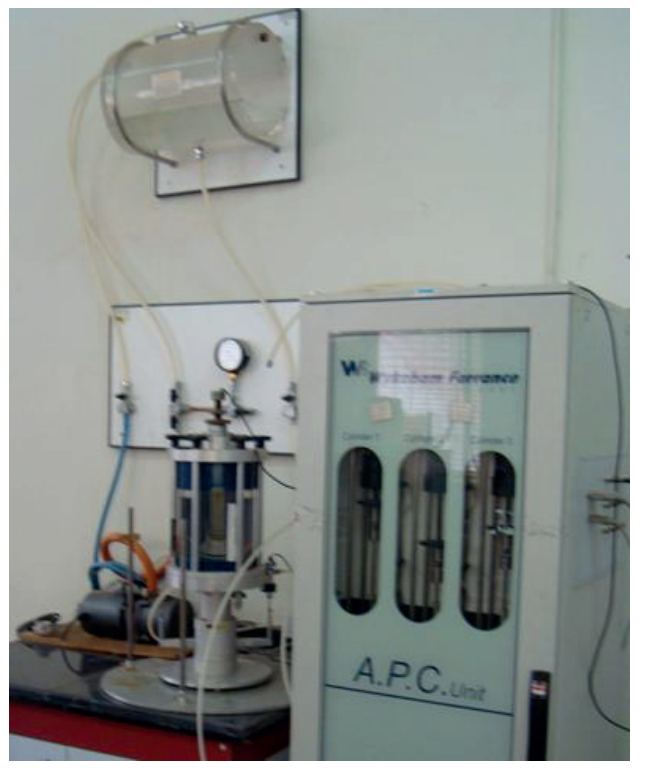

Fig. 2 Scheme of the modified Bishop-Wesley apparatus 
The pressure in each cylinder is controlled through a winding motor with very high precision. In order to measure and control pore water and air pressure independently, a ceramic disc with air entry pressure of 5 bar was used at the pedestal beneath the sample. Later, using the axis translation technique [12], matrix suction was effectively applied to the soil sample without cavitations. In this method, air pressure $\left(u_{a}\right)$ and water pressure $\left(u_{w}\right)$ are applied from the top and bottom of the sample such that the difference is considered to be equal to the degree of suction applied to the sample $\left(u_{a}-u_{w}\right)$. The net mean stress applied to the sample in this system is expressed by $\left(p-u_{a}\right)$. In general, using this developed device it is possible to examine unsaturated soil under different values of matrix suction and net mean stress. From the beginning of this test, it is possible to track total volume variations and water volume variations in the sample and therefore monitor the soil density variations behavior in wetting and drying processes.

\subsection{Tests procedure}

Prior to any test, the ceramic disc was saturated using a method similar to the method proposed by Fredlund and Rahardjo [5]. To this end, the cell was filled by de-aired water and then the cell pressure was increased up to $600 \mathrm{kPa}$. At that time, the water compartment beneath the ceramic was connected to atmosphere. The $600 \mathrm{kPa}$ difference between the pressure of the upper and lower surfaces of the ceramic led to the outward flow of water. After 10 hours, in order to drive out the air entrapped in the ceramic, the drainage valve beneath the ceramic was blocked for 2 hours. Therefore, the air inside the ceramic disc was dissolved into water at a pressure of $600 \mathrm{kPa}$. In order to ensure the saturation of the ceramic disc, this process of de-airing and saturation was iterated 6 times.

For test application, each sample was covered with two plastic membranes. In order to prevent spreading air between the two plastic membranes, some silicon grease was applied to their contact surfaces. Next, the sample on the ceramic disc was placed on the cell pedestal. The plastic membranes were secured and sealed to the pedestal using two washers. A porous stone and a loading cap were also put on top of the sample. After installation of the cell, a small axial load (5 kPa) was applied to the sample to protect and keep it in its place. In order to drive air out of the sample, $50 \mathrm{kPa}$ of water pressure was exerted on the sample through the base of the cell. However, the pressure on top of the sample was kept at atmospheric level to let the air flow out of the sample cap. At the time of de-airing, a cell pressure of $75 \mathrm{kPa}$ was applied to the soil sample to prevent its failure. After 72 hours of de-airing, the drainage valve above the sample was blocked for 24 hours to balance pore air pressure in the sample.

The soil-water characteristic curve (SWCC) for the sample was obtained through an unsaturated triaxial test under various levels of matrix suction as shown in Fig. 3. The soil sample was kept under a constant level of suction for at least 3 days until the rate of variation of water flowing into/out of the sample remained unchanged. According to the curve, the air entry value and air expulsion were obtained $44 \mathrm{kPa}$ (drying stage) and $22 \mathrm{kPa}$ (wetting stage), respectively.

Saturated (zero matrix suction) and unsaturated triaxial tests were conducted on soil samples in different stress paths. In order to perform the saturated triaxial test, the sample was first saturated using back pressure until B reached a value between 0.95 and 1 . The time required for saturation of soil samples was at least 3 days. Following the saturation phase, the samples were consolidated under effective stresses of 50,100, 200 and $400 \mathrm{kPa}$. In order to complete consolidation, the samples were kept under each of the aforementioned consolidation stresses for at least 24 hours.

The unsaturated triaxial test was performed on the soil samples in the drying and wetting phases. The first phase of the unsaturated test was focused on the application of matrix suction. First water pressure of $300 \mathrm{kPa}$ and air pressure of $300 \mathrm{kPa}$ were applied from the top and bottom of the sample, respectively. Afterwards, for the unsaturated samples air pressure was kept unchanged (at $300 \mathrm{kPa}$ ) while changes in matrix suction were made by decreasing water pressure beneath the sample. For the drying path, matrix suction was increased from zero (saturated condition) to $300 \mathrm{kPa}$. For the wetting path, the matrix suction was increased to $300 \mathrm{kPa}$ at first and then

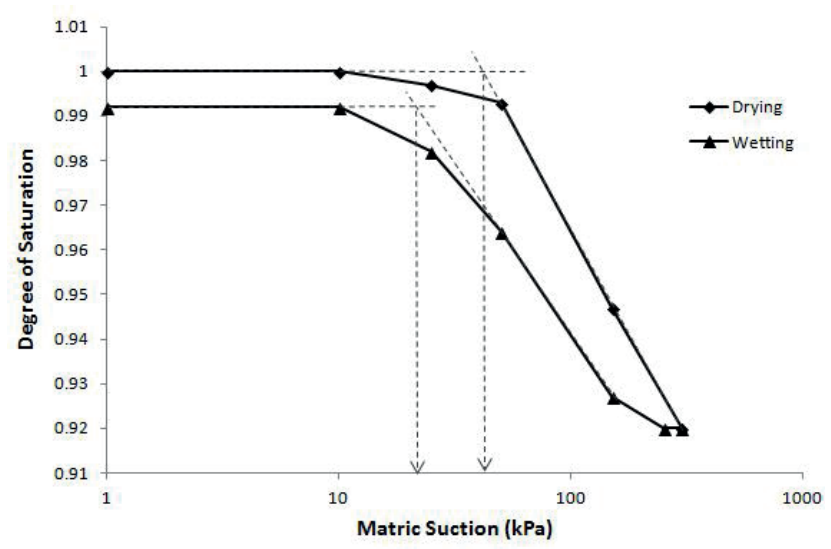

Fig. 3 Soil-water characteristic curve (SWCC) of the soil sample 
the degree of suction was reduced to zero along the wetting path. The requirement for the balance of the suction was to achieve variations of inflow or outflow water volume unchanged. The time required for balancing the matrix suction applied to the samples was at least 3 to 4 days. The required time depended on several factors such as soil permeability, initial matrix suction, compaction conditions, initial moisture content of soil the samples, and thickness of the ceramic disc. The soil samples were consolidated by increasing the cell pressure in increments. This process continued until the lateral effective stress reached the desired net mean stress. For each incremental loading, it is possible to let the resulting pore water pressure dissipate for at least 2 days (until the variations of water volume flowing out of the samples remains unchanged).

\section{Result and discussion}

\subsection{Effect of drying and wetting on effective stress}

In order to study the effect of drying and wetting on effective stress parameter, the results of unsaturated and saturated triaxial tests were employed. Figs. 4 and 5 illustrate the results of saturated triaxial tests. Fig. 4 also depicts the deviator stress $\left(q^{\prime}\right)$ - strain curves for 50, 100 and 200 $\mathrm{kPa}$ lateral effective stresses. Fig. 5 shows the critical state line (CSL) on the deviator stress $\left(q^{\prime}\right)$ - net mean stress $\left(p^{\prime}\right)$ plane. Coordinates of a point on the effective stress-deviator stress plane was obtained using saturated triaxial test results as well as the following relations. The gradient of the critical state line $(M)$ on the $p^{\prime}-q^{\prime}$ plane was calculated to be 0.82 .

$p^{\prime}=\sigma_{1}^{\prime}+2 \sigma_{3}^{\prime} / 3$

$q^{\prime}=\sigma_{1}^{\prime}-\sigma_{3}^{\prime}$

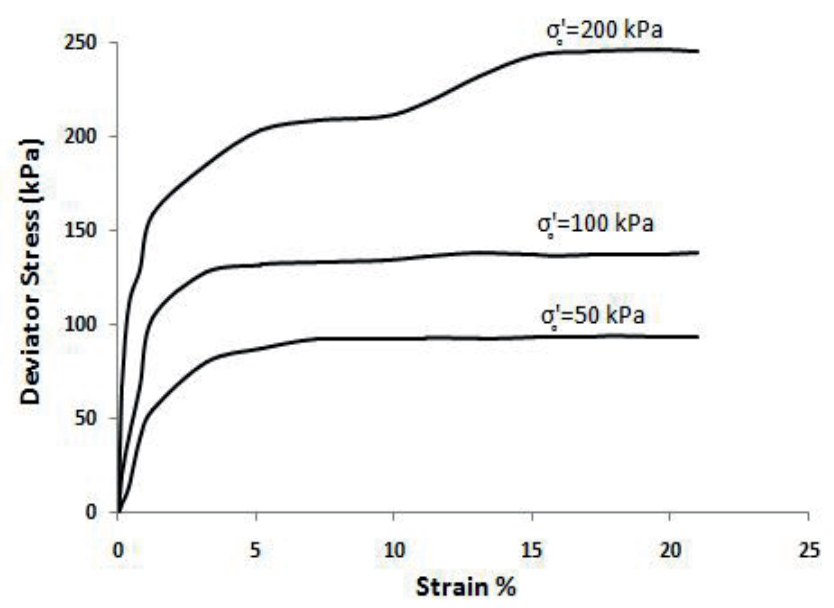

Fig. 4 Stress-strain curves (saturated Triaxial) where, $p^{\prime}$ denotes net mean stress and $\sigma_{1}^{\prime}$ denotes axial effective stress. Moreover, $\sigma_{3}{ }^{\prime}$ and $q^{\prime}$ represent lateral (or deviator) effective stress and deviator stress, respectively.

The stress-strain curves obtained from the results of unsaturated triaxial tests for various matrix suction levels in drying (increased suction) and wetting (decreased suction) paths are shown in Fig. 6. These diagrams demonstrate the strain hardening phenomenon. In addition, at

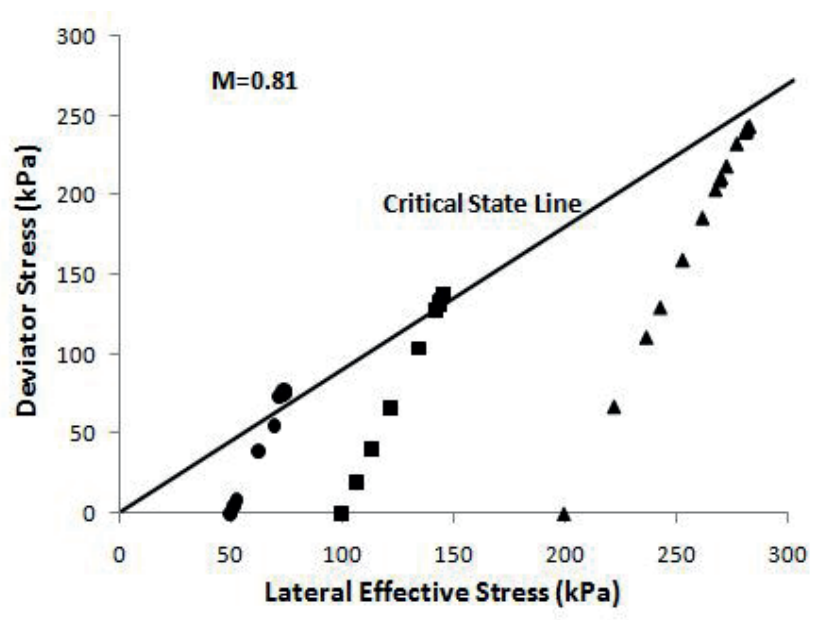

Fig. 5 Critical state line (saturated Triaxial)

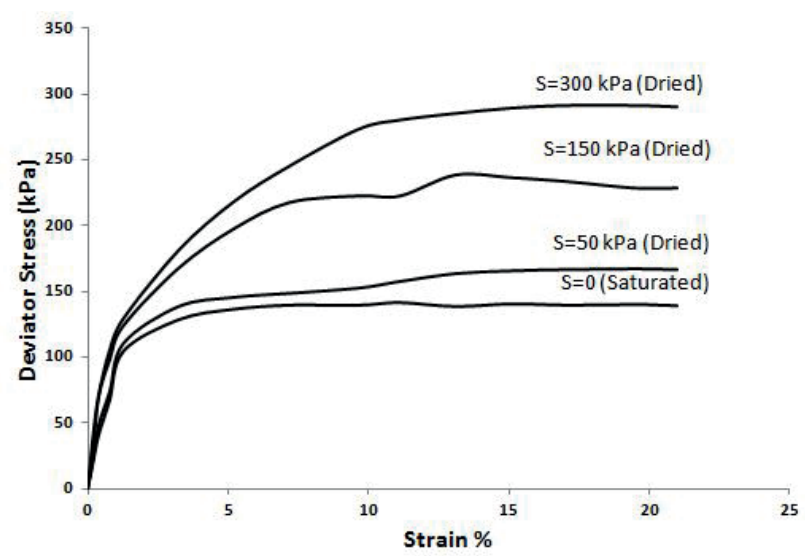

(a)

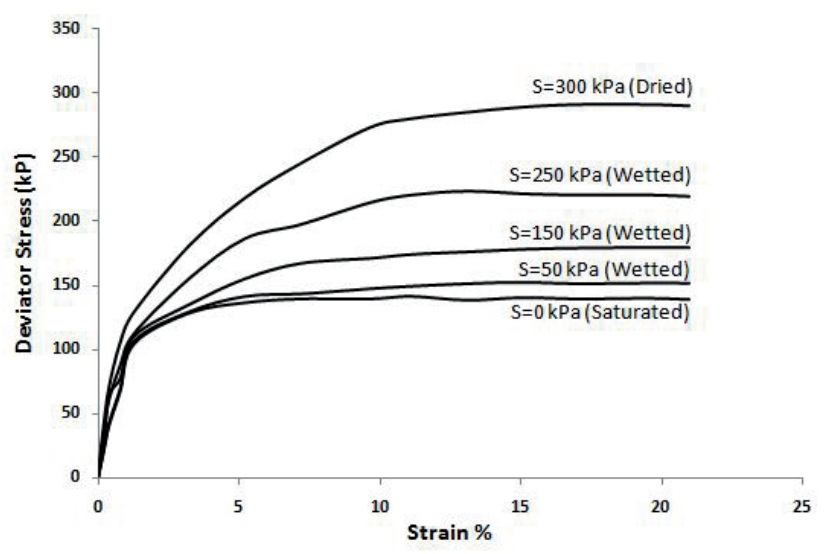

(b)

Fig. 6 Stress-strain curves: a) drying path and b) wetting path 
Table 2 Maximum effective stress in both drying and wetting paths

\begin{tabular}{lcc}
\hline \multirow{2}{*}{ Suction $(\mathrm{kPa})$} & \multicolumn{2}{c}{ Maximum effective stress $(\mathrm{kPa})$} \\
& Drying path & Wetting path \\
\hline 50 & 166.5 & 153 \\
150 & 239 & 179.5 \\
300 & 291 & 290 \\
\hline
\end{tabular}

the same matrix suction level, the stress-strain curve of the dried sample always lies above the stress-strain curve of the wetted sample. So, the effective stress is not equal for drying and wetting states even with unchanged degree of suction. This difference reflects the effect of hydraulic hysteresis on the effective stress of unsaturated soil. In this state, with the same suction, a higher level of effective stress is developed in the drying path than the wetting path as shown in Table 2 .

To gain the effect of drying and wetting on the effective stress, the effective stress parameter $(\chi)$ was calculated for drying and wetting paths and then the results were compared to those of other researchers. According to the observations recorded by Uchaipichat [13], the $\chi$ parameter can be calculated by assuming that the gradient of the critical state line (on the deviator stress-net mean stress plane) is independent of matrix suction. Therefore, using the expression of effective stress in Eq. (1), the $\chi$ parameter can be obtained as follows:

$\chi=\frac{\frac{q_{f}}{M}-\left(p_{f}-u_{f}\right)}{\left(u_{a}-u_{w}\right)}$,

where, $p_{f}$ and $q_{f}$ denote the net mean stress and effective stress in the critical state, respectively. $M$ also shows the gradient of the critical state line.

Values of the $\chi$ parameter for the drying and wetting paths were obtained using Eq. (6) and the test results as shown in Fig. 7. From the figure, $\chi$ parameter in the two drying and wetting paths is different at the same suction. The value of this parameter in the drying path is higher than the wetting path. This indicates that the effective stress is affected by the hydraulic hysteresis phenomenon through the $\chi$ parameter. This phenomenon is due to the fact that in the same water content, the soil sample in the drying path has more suction than the wetting path, which causes more effective stress in the drying path.

Moreover, using Eq. (2), which was proposed by Khalili et al. [4], and Bishop's [2] theory $(\chi-S r)$, the values of the $\chi$ parameter were calculated for the drying and wetting paths. The resulting values were also compared to

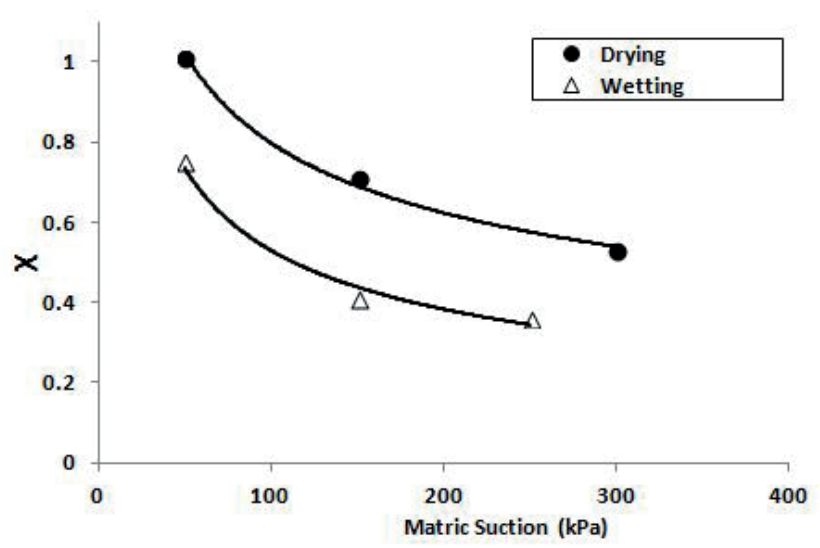

Fig. 7 Hysteresis diagram for $\chi$

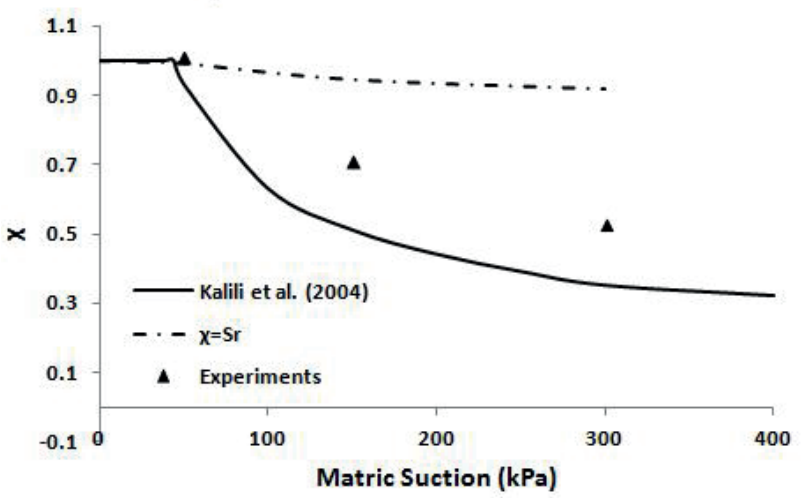

(a)

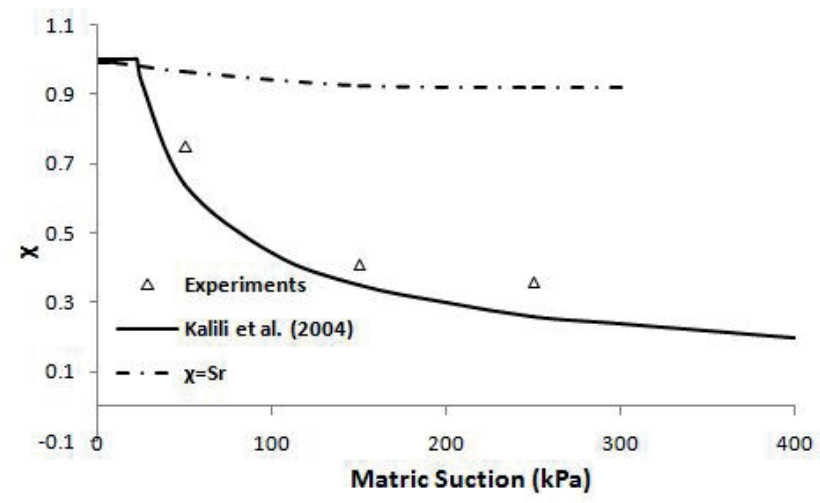

(b)

Fig. $8 \chi$ - suction a) drying path b) wetting path

the laboratory results. The difference between laboratory results and the results obtained by Eq. (2) for the $\chi$ parameter was from 0.08 to 0.28 and 0.06 to 0.11 in the drying and wetting paths, respectively. According to Fig. 8, the laboratory results are properly similar to the results of the study by Khalili et al. [4]. In other words, these results confirm the theory developed by Khalili et al. [4] for the soil. Evidently, the first Bishop's theory $(\chi-S r)$ is not properly applicable to unsaturated soils. 


\subsection{Effect of drying and wetting on soil compressibility}

Values of preconsolidation stress can be derived from compressibility curves (Figs. 9 and 10). Values of preconsolidation pressure were obtained from the failure point of consolidation curves in the triaxial tests. The intersection of the elastic compression slope and the plastic compression slope was defined as the preconsolidation stress. This method was also employed by Lloret et al. [14].

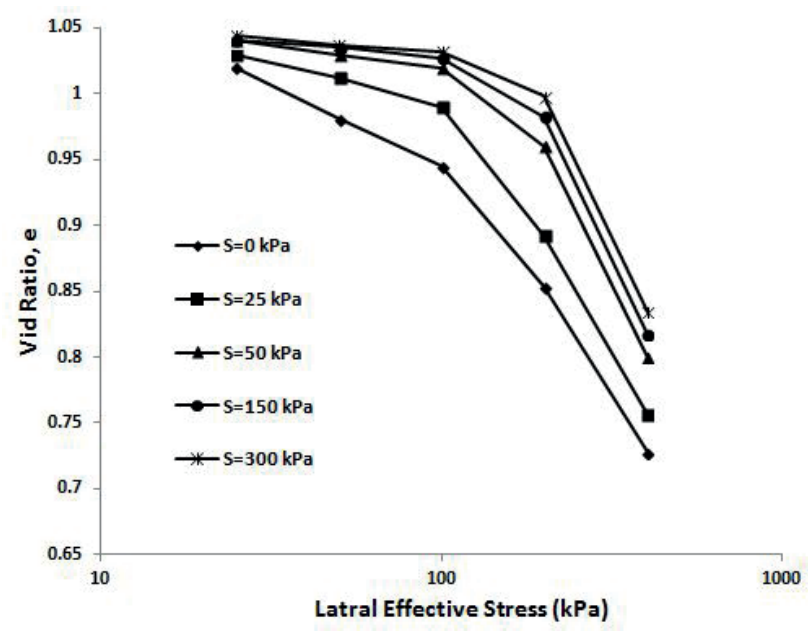

(a)

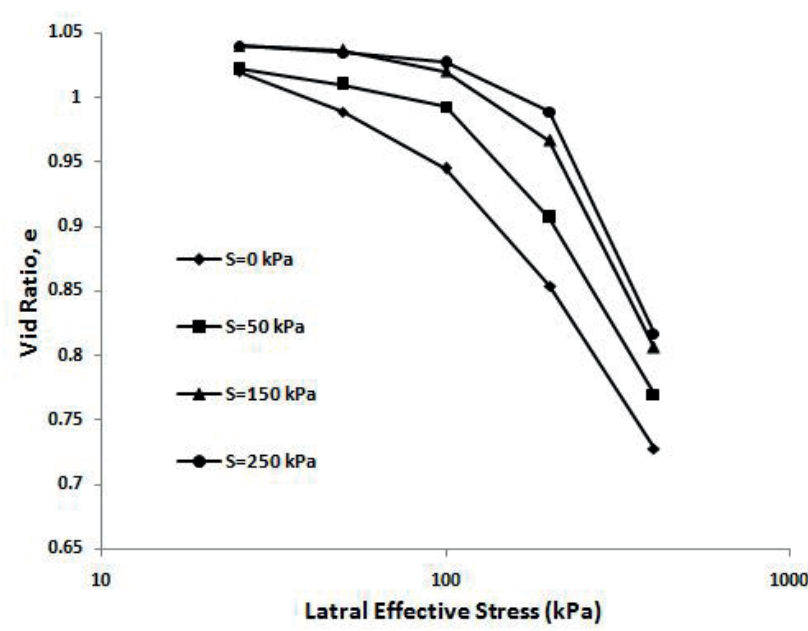

(b)

Fig. 9 Compression curves: a) drying path b) wetting path

\section{References}

[1] Yilmaz, Y., Bahari Kheirjouy, A. B., Akgungor, A. P. "Investigation of the Effect of Different Saturation Methods on the Undrained Shear Strength of a Clayey Soil Compacted with Standard and Modified Proctor Energies", Periodica Polytechnica Civil Engineering, 60(3), pp. 323-329, 2016.

https://doi.org/10.3311/PPci.8891

[2] Bishop, A. W. "The principle of effective stress", Teknisk Ukeblad, 106(39), pp. 859-863, 1959.

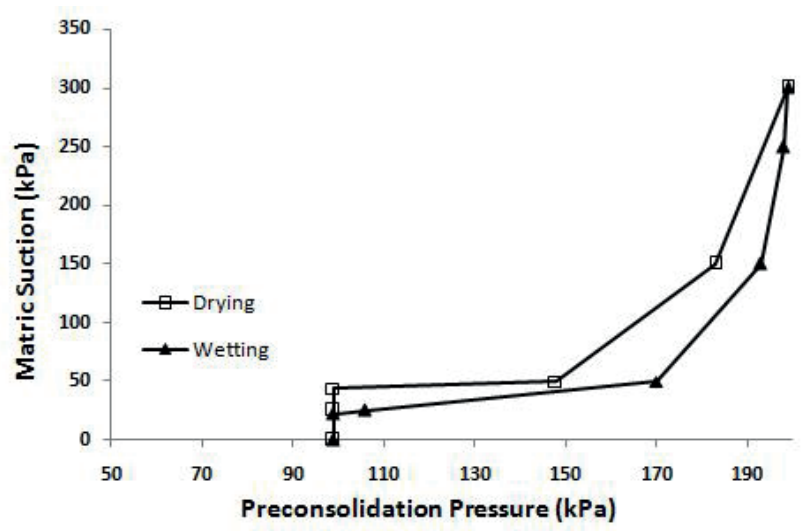

Fig. 10 Loading-collapse curve (LC)

Fig. 9(a, b) show the compression curves at different matric suction along drying and wetting paths, respectively. The data shows a shift in normal compression curve to higher effective stresses with increasing matric suction in both cases.

\section{Conclusions}

Results of the present study indicated that values of the effective stress parameter $(\chi)$ for unsaturated fine-grained soil varied in drying and wetting paths with an equal level of matrix suction. This difference reflects the effect of hydraulic hysteresis on the effective stress of unsaturated fine-grained soils. In general, values of the $\chi$ parameter for the drying path were larger than values for the wetting path. Research results also showed that the behavior of the clayey fine-grained soil in the unsaturated state was very similar to the behavior obtained by the model proposed by Khalili et al. [4]. Therefore, Bishop's effective stress parameter cannot be used for this type of soil. On the other hand, the loading-collapse (LC) curves for the drying and wetting stages differed even with same degrees of matrix suction.

\section{Acknowledgement}

Authors are so thankful of Yasuj Branch, Islamic Azad University for the funding support of the research.

[3] Fredlund, D. G., Morgenstern, N. R., Widger, R. A. "The shear strength of unsaturated soils", Canadian Geotechnical Journal, 15(3), pp. 313-321, 1978.

https://doi.org/10.1139/t78-029

[4] Khalili, N., Geiser, F., Blight, G. E. "Effective Stress in Unsaturated Soil: Review whit New Evidence", International Journal of Geomechanics, 4(2), pp. 115-126, 2004.

https://doi.org/10.1061/(ASCE)1532-3641(2004)4:2(115) 
[5] Fredlund, D. G., Rahardjo, H. "Soil Mechanics for Unsaturated Soils", John Wiley \& Sons, New York, NY, USA, 1993. https://doi.org/10.1002/9780470172759

[6] Khalili, N., Khabbaz, M. H. "A unique relationship for $\chi$ for the determination of the shear strength of unsaturated soils", Géotechnique, 48(5), pp. 681-687, 1998.

https://doi.org/10.1680/geot.1998.48.5.681

[7] Loret, B., Khalili, N. "An effective stress elastic-plastic model for unsaturated porous media", Mechanics of Materials, 34(2), pp. 97-116, 2002.

https://doi.org/10.1016/S0167-6636(01)00092-8

[8] Kholghifard, M., Ahmad, K., Ali, N., Kassim, A., Kalatehjari, R., Babakanpour, F. "Temperature effect on compression and collapsibility of residual granitic soil", Građevinar, 66(3), pp. 191-196, 2014. https://doi.org/10.14256/JCE.947.2013

[9] Kholghifard, M., Ahmad, K., Ali, N., Kassim, A., Kalatehjari, R. "Collapse/Swell Potential of Residual Laterite Soil Due to Wetting and Drying-wetting Cycles", National Academy Science Letters, 37(2), pp. 147-153, 2014.

https://doi.org/10.1007/s40009-013-0221-4
[10] ASTM "ASTM D6836 - 16 Standard Test Methods for Determination of the Soil Water Characteristic Curve for Desorption Using Hanging Column, Pressure Extractor, Chilled Mirror Hygrometer, or Centrifuge", ASTM International, West Conshohocken, PA, USA, 2008.

https://doi.org/10.1520/D6836-16

[11] Bishop, A. W., Wesley, L. D. "A hydraulic triaxial apparatus for controlled stress path testing", Géotechnique, 25(4), pp. 657-670, 1975. https://doi.org/10.1680/geot.1975.25.4.657

[12] Hilf, J. W. "An investigation of pore-water pressure in compacted cohesive soil", PhD Thesis, Graduate School University of Colorado Boulder, 1956.

[13] Uchaipichat, A. "Influence of Hydraulic Hysteresis on Effective Stress in Unsaturated Clay", International Journal of Environmental and Earth Sciences, 4(12), pp. 639-643, 2010. https://doi.org/10.5281/zenodo.1060976

[14] Lloret, A., Villar, M. V., Sánchez, M., Gens, A., Pintado, X., Alonso, E. E. "Mechanical behavior of heavily compacted bentonite under high suction changes", Géotechnique, 53(1), pp. 27-40, 2003. https://doi.org/10.1680/geot.2003.53.1.27 